\title{
Maximizing the general success of cecal intubation during propofol sedation in a multi- endoscopist academic centre
}

\author{
Fabrizio Cardin ${ }^{1 *}$, Nadia Minicuci ${ }^{2}$, Alessandra Andreotti ${ }^{2}$, Elena Pinetti ${ }^{3}$, Federico Campigotto ${ }^{2}$, Barbara M Donà ${ }^{4}$, \\ Bruno Martella', Oreste Terranova ${ }^{1}$
}

\begin{abstract}
Background: Achieving the target of 95\% colonoscopy completion rate at centres conducting colorectal screening programs is an important issue. Large centres and teaching hospitals employing endoscopists with different levels of training and expertise risk achieving worse results. Deep sedation with propofol in routine colonoscopy could maximize the results of cecal intubation.
\end{abstract}

Methods: The present study on the experience of a single centre focused on estimating the overall completion rate of colonoscopies performed under routine propofol sedation at a large teaching hospital with many operators involved, and on assessing the factors that influence the success rate of the procedure and how to improve this performance, analyzing the aspects relating to using of deep sedation. Twenty-one endoscopists, classified by their level of specialization in colonoscopic practice, performed 1381 colonoscopies under deep sedation. All actions needed for the anaesthesiologist to restore adequate oxygenation or hemodynamics, even for transient changes, were recorded.

Results: The "crude" overall completion rate was 93.3\%. This finding shows that with routine deep sedation, the colonoscopy completion rate nears, but still does not reach, the target performance for colonoscopic screening programs, at centers where colonoscopists of difference experience are employed in such programs. Factors interfering with cecal intubation were: inadequate colon cleansing, endoscopists' expertise in colonoscopic practice, patients' body weight under $60 \mathrm{~kg}$ or age over 71 years, and the need for active intervention by the anaesthesiologist. The most favourable situation - a patient less than 71 years old with a body weight over $60 \mathrm{~kg}$, an adequate bowel preparation, a "highly experienced specialist" performing the test, and no need for active anaesthesiological intervention during the procedure - coincided with a $98.8 \%$ probability of the colonoscopy being completed.

Conclusions: With routine deep sedation, the colonoscopy completion rate nears the target performance for colonoscopic screening programs, at centers where colonoscopists of difference experience are employed in such programs. Organizing the daily workload to prevent negative factors affecting the success rate from occurring in combination may enable up to $85 \%$ of incomplete procedures to be converted into successful colonoscopies.

\section{Background}

In colorectal cancer screening, successful colonoscopy is related to the polyps detection rate and the percentage of complete colon examinations achieved with cecal intubation. Both factors depend on technical issues and

\footnotetext{
* Correspondence: fabrizio.cardin@sanita.padova.it

${ }^{1}$ Geriatrics Department, Geriatric Surgery Unit, General Hospital, Padova, Italy Full list of author information is available at the end of the article
}

the endoscopist's performance [1]. The quality standard for the polyps detection rate (set at $25 \%$ in men and $15 \%$ in women) is related to the withdrawal time and differences seem to be due more to endoscopists' individual sensitivity than to their technical expertise [2].

Completed colonoscopy rates of $97-99 \%$ have been reported and, although a rate of $90 \%$ is acceptable in routine clinical activity, it is best to aim for at least $95 \%$

\section{()


of completed colonoscopies in screening programs [3]. Various technical factors play a part, such as the calibre [4] or stiffness [5] of the instrument used, and the time of day when the test is scheduled [6], but the endoscopists' experience and the number of endoscopies they have already performed have an important influence on the success of the test [7].

Some endoscopy units achieve good results because the activity is handled by a single, dedicated endoscopist $[8,9]$, while large teaching centres reach lower quality indicators for their colonoscopy activities [10]. In large hospitals, the overall colonoscopy completion rates are influenced by the procedure being implemented by trainee doctors and by endoscopists from different specialities (gastroenterological, surgical, or internal medicine). In such cases, strategies have been proposed to improve performance based on auditing programs, adjusting the various endoscopists' workload in the light of their results [11], or having trainees use auxiliary devices to facilitate cecal intubation [12].

In hospitals with a large number of practising colonoscopists, a rapid strategy to optimize global performance and achieve an acceptable number of complete colonoscopies with minimal patient discomfort could be to routinely use deep sedation with propofol. This is considered a procedure with an acceptable safety profile [13], but the extensive use of such a method to improve technical results is a debatable issue [14]. The aim of this study was to present the results of routine propofol sedation for colonoscopy at a large teaching hospital where a large number of doctors with differing levels of expertise are involved in colonoscopy activities. We also assessed the factors influencing the success rate of the procedure and ways to improve performance, analyzing the complementary aspects relating to the use of deep sedation.

\section{Methods}

We investigated the routine activities at an endoscopy centre at Padova University teaching hospital, consecutively enrolling all patients who had a colonoscopy under deep sedation in the study over a period of one year (February 2007 to February 2008).

Subject to patients' informed written consent, their clinical history was recorded to identify any anaesthesiological or procedural risks, collecting data on: a) nongastrointestinal conditions; b) allergies or side effects of previously-used anaesthetics; c) ASA status [15]. Information was then recorded on the completeness of the colonoscopy, the propofol dosage used and any adverse events on a case report form (CRF) formulated specifically for the purposes of the study. The health professionals responsible for compiling the CRF were unaware that they were participating in the study. Patients were not enrolled in the study if they refused to sign the consent form or if they were willing to undergo colonoscopy without sedation, or if the endoscopist preferred for clinical or technical reasons to perform the colonoscopy without sedation (e.g. as a follow-up procedure in a patient who had already tolerated the test well, or in a patient with an operated colon).

\section{Institutional review board approval}

According to the guidelines of Italian Agency of Drugs (AIFA) the observational studies which use retrospective data or materials do not require formal approval by the local Ethics Committee.

\section{Endoscopist classification}

The endoscopists involved in the colonoscopy procedures were classified according to their level of experience, grouped into three categories, defined as: 1) "less experienced non-specialists" if they had been performing endoscopies for less than 10 years; 2) "more experienced non-specialists" if they had been performing endoscopies for more than 10 years but were not exclusively dedicated to endoscopic activities (performing up to two endoscopic sessions a week); and 3) "highly experienced specialists" if they had been performing endoscopies for more than 10 years and handled at least four endoscopic sessions a week (the scheduled number of colonoscopies per session is four). There were three gastroenterologists involved; all the other operators were surgeons.

\section{Propofol sedation}

Before colonoscopy, all patients received an initial induction dose of propofol $(0.5-1 \mathrm{mg} / \mathrm{Kg})$ to induce a lethargic response to oral stimuli and no corneal reflex. During the procedure, propofol was titrated by the anaesthetist with intermittent boluses if patients showed signs of more than mild discomfort and occasional grimacing, or became agitated or were clearly in pain at any stage of the procedure.

Patient monitoring was started before sedation and continued until patients recovered to check for any episodes of hypotension, hypoxemia or cardiac arrhythmia, which were recorded in the CRF and treated pharmacologically, where necessary.

The patients' preparatory colon cleansing consisted in ingesting four litres of Macrogol solution at home on the day before the colonoscopy. Their bowel preparation was classified as: 1) "adequate", 2) "with residual matter" or 3) "inadequate" when faeces prevented the continuation of the examination.

\section{Definition of complete colonoscopy}

The main efficacy endpoint was the completeness of the colonoscopy, defined as the identification of a normal 
cecal anatomy or ileocolic anastomosis. When colonoscopy was interrupted due to organic stenoses, it was considered as complete, as stated by Rex et al. (3). Any anaesthesiological, pharmacological or manual measures taken by the anaesthetist were recorded and classified as "active anaesthesiological intervention" (AAI).

Hemodynamic monitoring data were used to determine the duration of the colonoscopy.

\section{Sample size determination}

In the literature[3], the colonoscopy completion rate is reportedly around $97 \%$. The PASS 2008 software was used to determine the sample size needed for our study, which was identified as a sample size of 1216 in order to produce a two-sided 95\% confidence interval with a width of 0.020 (CI 96\%-98\%) when the sample proportion is 0.970 . Assuming a $20 \%$ drop-out rate, 1500 records were analyzed vis-à-vis the inclusion criteria.

\section{Statistical analysis}

Summary statistics (mean values or percentages) were compared by completeness-of-colonoscopy groups using the $t$-test (after checking the homoschedasticity) and the chi-square $\left(\chi^{2}\right)$ test, respectively. If they were not applicable, analogous non-parametric tests were used (Wilcoxon's rank-sum test or Fisher's exact test).

Predictors of an incomplete colonoscopy were investigated by multivariate stepwise ( $\mathrm{p}$-entry $=0.15$ ) logistic regression analysis, including sex, age, body weight, ASA category, total dosage of propofol administered, duration of the procedure, endoscopists' experience levels, bowel preparation, and any AAI as predictors.

The SAS statistical software, rel. 9.1.3, was used for the analysis. A p-value $<0.05$ was used to establish statistical significance.

\section{Results}

During the study period, a total of 2,027 colonoscopies were performed, 1,381 of them under deep sedation and the latter formed the object of this study (Table 1). The incomplete procedures amounted to 92 and 67 of these were incomplete for technical reasons, 25 due to inadequate bowel preparation. Older age was statistically associated with incomplete colonoscopy (64.2 vs 60.5 years)

There were 77 AAI during the procedures (5.2\% among the complete colonoscopies and $10.9 \%$ among the incomplete colonoscopies; $\mathrm{p}$-value $=0.02$ ) to deal with 28 respiratory(solved using mask ventilation, without any need for intubation) and 39 hemodynamic problems, 8 episodes of regurgitation, and 2 of allergic reactions (the patients were simultaneously treated with antibiotic prophylaxis). We observed two complications of the endoscopic procedure, i.e. one perforation and one post-polypectomy hemorrhage. Polypectomy was performed during 231 procedures.

A statistically significant association emerged between ASA scores and completeness of colonoscopy ( $\mathrm{p}$-value = 0.002): $53.9 \%$ of patients with completed colonoscopies and $44.6 \%$ of those with incomplete colonoscopies had an ASA score of 2; the corresponding percentages among the patients with ASA scores of 3 or 4 were $7.8 \%$ and $18.5 \%$.

The mean total doses of propofol administered differed statistically between the two groups with a p-value of 0.02 (191.2 mg vs $172.1 \mathrm{mg}$, respectively).

The endoscopists' levels of experience were unevenly distributed between the two groups, with a greater prevalence of highly experienced specialists associated with the completed colonoscopy group ( $24 \%$ vs $8.7 \%$, p-value $<0.0001)$.

Sex, body weight, duration of the procedure, $\mathrm{O} 2 \mathrm{l} / \mathrm{m}$ and SPO2 variables were not associated with the completeness of colonoscopy.

About $73 \%$ of patients with completed colonoscopies had adequately prepared bowels, $24 \%$ of patients had residual matter and $3 \%$ of patients had inadequately cleansed bowels; the corresponding percentages among patients with incomplete colonoscopies were: $47 \%$, $26 \%$ and $27 \%$, revealing a statistical association (p-value < $0.0001)$.

"Less experienced non-specialist" endoscopists were also more frequently associated with cases of inadequate bowel preparation (Table 2).

Logistic regression analysis (Table 3 ) showed that patients with inadequately prepared bowels had an 11fold increase in the risk of incomplete colonoscopy by comparison with patients with an adequate bowel preparation, while the risk associated with the presence of residual matter was not significant. Having a colonoscopy done by a less experienced endoscopist coincided with a 5 -fold increase in the risk of an incomplete procedure by comparison with colonoscopies handled by a highly experienced specialist; this risk dropped to a 2 -fold increase if the test was performed by a more experienced non-specialist.

The need for AAI and age over 71 years coincided with a 2.7 -fold and a 2.1 -fold increase in the risk of a colonoscopy not being completed; weighing less than 60 $\mathrm{kg}$ also emerged as a risk factor $(\mathrm{OR}=1.89)$.

The logistic model had an area under the ROC curve of $77.8 \%$ and the value of the Hosmer-Lemeshow goodness of fit statistic was 2.05 , with a corresponding $\mathrm{p}$-value of 0.91, indicating that the model seems to fit quite well. None of the other variables contributed to the predictive power of the model.

To gain a better understanding of the contribution of the various factors involved in the completion of a 
Table 1 Distribution of the main characteristics by completeness of colonoscopy

\begin{tabular}{|c|c|c|c|}
\hline & \multicolumn{2}{|c|}{ Complete colonoscopy } & \multirow[t]{2}{*}{$P$ value } \\
\hline & $\begin{array}{c}\text { Yes } \\
(n=1289)\end{array}$ & $\begin{array}{c}\text { No } \\
(n=92)\end{array}$ & \\
\hline Sex $(\%)$ & & & Ns \\
\hline Female & $53.4 \%$ & $54.3 \%$ & \\
\hline Age & & & 0.007 \\
\hline Mean \pm SD & $60.5 \pm 13.6$ & $64.2 \pm 15.3$ & \\
\hline Range & 14-95 & 21-91 & \\
\hline Body Weight (kg) & & & Ns \\
\hline Mean $\pm S D$ & $71.7 \pm 14.1$ & $69.8 \pm 15.5$ & \\
\hline Range & 37-135 & $42-120$ & \\
\hline ASA (\%) & & & 0.002 \\
\hline 1 & $38.3 \%$ & $36.9 \%$ & \\
\hline 2 & $53.9 \%$ & $44.6 \%$ & \\
\hline $3+4$ & $7.8 \%$ & $18.5 \%$ & \\
\hline Propofol (mg) & & & 0.02 \\
\hline Mean \pm SD & $191.2 \pm 78.3$ & $172.1 \pm 91.6$ & \\
\hline Range & 30-650 & 20-430 & \\
\hline Duration of procedure (minutes) & & & Ns \\
\hline Mean \pm SD & $24.4 \pm 11.1$ & $23.8 \pm 13.4$ & \\
\hline Range & 5-85 & 4-70 & \\
\hline $\mathrm{O} 2 \mathrm{l} / \mathrm{m}(\%)$ & & & Ns \\
\hline$\leq 4 \mathrm{l} / \mathrm{m}$ & $95.4 \%(n=992)$ & $96 \%(n=72)$ & \\
\hline$>4 \mathrm{l} / \mathrm{m}$ & $4.6 \%(n=48)$ & $4 \%(n=3)$ & \\
\hline Missing (n) & 249 & 17 & \\
\hline SPO2 & & & Ns \\
\hline Mean $\pm S D$ & $98.54 \pm 1.73$ & $98.46 \pm 1.77$ & \\
\hline Range & $80-100$ & 89-100 & \\
\hline Missing (n) & 83 & 6 & \\
\hline Presence of $\mathrm{AAI}(\%)$ & & & 0.02 \\
\hline Yes & $5.2 \%$ & $10.9 \%$ & \\
\hline Endoscopists $(n=21)(\%)$ & & & $<0.0001$ \\
\hline Less experienced non-specialists $(n=7)$ & $9.7 \%$ & $25.0 \%$ & \\
\hline More experienced non-specialists $(n=8)$ & $66.1 \%$ & $66.3 \%$ & \\
\hline Highly experienced specialists $(n=6)$ & $24.2 \%$ & $8.7 \%$ & \\
\hline Bowel preparation (\%) & & & $<0.0001$ \\
\hline Adequate & $72.7 \%$ & $46.7 \%$ & \\
\hline With residual matter & $24.1 \%$ & $26.1 \%$ & \\
\hline Inadequate & $3.2 \%$ & $27.2 \%$ & \\
\hline Polypectomy (\%) & & & 0.03 \\
\hline Yes & $17.3 \%$ & $8.7 \%$ & \\
\hline
\end{tabular}

colonoscopy, the logistic regression model was used to calculate the probabilities of complete colonoscopy according to different combinations of values of these predictors. The most favourable situation - a patient less than 71 years old with a body weight over $60 \mathrm{~kg}$, an adequate bowel preparation, a "highly experienced specialist" performing the test, and no need for AAI during the procedure - coincided with a $98.8 \%$ probability of the colonoscopy being completed. The probabilities related to all other possible combinations (71 in all) of the values of these predictors were computed and the \% variations between each combination and the most favourable situation were calculated. For example, the second most favourable situation (a patient less than 71 years old with a body weight over $60 \mathrm{~kg}$, an adequate bowel preparation, a "more experienced non-specialist" performing the test, and no need for AAI during the procedure) carried a probability of successful 
Table 2 Experience level of the endoscopists versus the bowel preparation ( $N$ )

\begin{tabular}{|c|c|c|c|c|}
\hline \multirow[b]{2}{*}{ Endoscopist } & \multicolumn{3}{|c|}{ Bowel preparation } & \multirow[b]{2}{*}{ Tota } \\
\hline & Adequate & $\begin{array}{l}\text { Presence of } \\
\text { residual } \\
\text { matter }\end{array}$ & Inadequate & \\
\hline $\begin{array}{l}\text { Less experienced non- } \\
\text { specialist }\end{array}$ & 95 & 36 & 17 & 148 \\
\hline $\begin{array}{l}\text { More experienced non- } \\
\text { specialist }\end{array}$ & 632 & 240 & 41 & 913 \\
\hline $\begin{array}{l}\text { Highly experienced } \\
\text { specialist }\end{array}$ & 253 & 59 & 8 & 320 \\
\hline Total & 980 & 335 & 66 & 1381 \\
\hline
\end{tabular}

colonoscopy of $96.7 \%$ with a $1.7 \%$ variation with respect to the most favourable situation. This means that the involvement of a "more experienced non-specialist" (symbol E, Table 4) reduces the probability of success by nearly $2 \%$. If we consider the case of a combination of a less experienced non-specialist and the need for AAI (EEA), the difference increases to $14.2 \%$. On the other hand, if the patient's bowel preparation is also inadequate, these same two factors (EEA) reduce the probability of success by $65 \%$.

These findings are graphed in Figure 1 by patient's age and body weight categories (unmodifiable predictors) and bowel preparation.

The greatest variation (more than $85 \%$ ) is recorded for a patient over 71 years old with a body weight below 60 $\mathrm{kg}$ and inadequate bowel preparation, needing AAI during a procedure conducted by a less experienced nonspecialist.

\section{Discussion}

It has already been emphasized that the colonoscopy completion rate is important for more than just academic reasons [8] and one important reason is that a completed colonoscopy reduces the likelihood of an advanced colorectal-cancer being detected later on [16].

Table 3 Odds ratios and $95 \% \mathrm{Cl}$ for incomplete colonoscopies

\begin{tabular}{lccc}
\hline & Odds Ratio & $\mathbf{9 5 \%} \mathbf{~ C l}$ & P value \\
\hline Age $\geq 71$ years old & 2.09 & $1.31-3.32$ & 0.002 \\
Body weight $<60 \mathrm{~kg}$ & 1.89 & $1.14-3.11$ & 0.013 \\
Highly experienced specialist & 1 & & \\
More experienced non-specialist & 2.47 & $1.15-5.34$ & 0.021 \\
Less experienced non-specialist & 5.19 & $2.17-12.41$ & 0.0002 \\
Adequate bowel preparation & 1 & & \\
Presence of residual matter & 1.59 & $0.94-2.68$ & 0.08 \\
Inadequate bowel preparation & 10.81 & $5.86-19.94$ & $<0.0001$ \\
Presence of AAl & 2.79 & $1.21-6.38$ & 0.015 \\
\hline
\end{tabular}

In this report on a single centre's experience of colonoscopies systematically associated with deep sedation with propofol, the global success rate achieved by 21 endoscopists working at the same endoscopic centre with different levels of expertise and training was $93 \%$.

The factors negatively influencing the success of the test were: a patient's small body size, age over 71 years, inadequate colonic cleansing and the need for AAI during deep sedation. For the purposes of this study, we did not correct the performance rate by excluding colonoscopies in which cecal intubation had been prevented by the presence of faecal material, because our aim was to establish the crude success rate for colonoscopy under deep sedation. It is worth adding here that more tests were interrupted due to poor cleansing issues when less expert endoscopists were involved.

Two complications of endoscopy (one perforation and one post-polypectomy haemorrhage) were recorded during the study period, a prevalence similar to that of other reports [17]. We used a broad definition of "adverse events" during colonoscopy under deep sedation, recording all action taken by the anaesthetist to restore adequate oxygenation or hemodynamics, even for short-lived monitoring problems, because such situations might influence the procedure or have to do with longer probe insertion times necessitating further propofol infusions. No hemodynamic resuscitation was needed and there were no major clinical sequelae after sedation.

One of the limits of this study is that we were not in a position to compare how different colonoscopic methods might improve the colonoscopy completion rate.

Although ours was an observational study on the controversial issue of the routine use of deep sedation for colonoscopies, it had the advantage of referring to a recognized target (i.e. 95\% cecal intubations in colonoscopies for screening purposes). Other published series adopted a different approach, achieving a different gap between their results and the 95\% target [18-20].

The performance measurement showed that the endoscopist's skill influences the success of colonoscopies even when deep sedation is used. In a clinical setting, this poses problems that have already been studied and overcome using quality improvement programs and auditing cycles [11]. All our endoscopists had gained experience during weekly sessions for more than a year, implementing 200 procedures alone (a number recognized as being sufficient to achieve a satisfactory performance in screening programs)[21]. When it comes to screening programs, the endoscopists' different levels of experience carry a different weight from the situation in routine clinical practice because the most important problem is often the shortage of operators. Solutions have to be found to deal with the problems of the burden of colonoscopies to perform and increasingly long 
Table 4 Description of the symbols used in the Figure 1

\begin{tabular}{|c|c|}
\hline Symbol & Description \\
\hline $\mathrm{E}$ & Presence of a more-experienced non specialist (vs highly-experienced specialist) \\
\hline A & Presence of AAI (vs none) \\
\hline EE & Presence of a less-experienced non specialist (vs highly-experienced specialist) \\
\hline EA & Presence of a more-experienced non specialist and AAI (vs highly-experienced specialist and no AAI) \\
\hline EEA & Presence of a less-experienced non specialist and AAI (vs highly-experienced specialist and no AAI) \\
\hline
\end{tabular}

waiting lists, which is why colonoscopies may be performed by gastroenterologists, clinical assistants, trainee gastroenterologists or nurses in some countries [22].

The aim of our study, however, was to ascertain whether using propofol sedation enables the standard to be reached in screening programs, when it is necessary to employ many endoscopists who are likely to have different levels of expertise.

Success rate has been seen as an expression of "technical machismo" [8] and some authors suggest that it should not be influenced by patient-related factors and that, in any case, a trained endoscopist should be able to complete $95 \%$ of colonoscopies successfully [23]. We considered it important to demonstrate that patients' weight and age, as already mentioned in other studies $[24,25]$ without deep sedation, are factors that also predict incomplete colonoscopies among series of colonoscopies performed under deep sedation at a busy teaching hospital service, where endoscopists of different abilities are at work.

Different strategies can be used to improve the quality of colonoscopic screening programs. We chose to consider the role of routine deep sedation. Propofol was preferred as a sedative because previous observational studies using other drugs for sedation during colonoscopy in almost $94 \%$ of the sample had still reported unacceptably low success rates [26]. In addition, it has recently been demonstrated that deep sedation enhances the polyps detection rate [27].

A weakness of our study is that we did not perform a thorough cost-benefit analysis, particularly as concerns the need for extra personnel to manage sedation. This issue depends largely on differences in the compensation awarded by national health systems and on their related

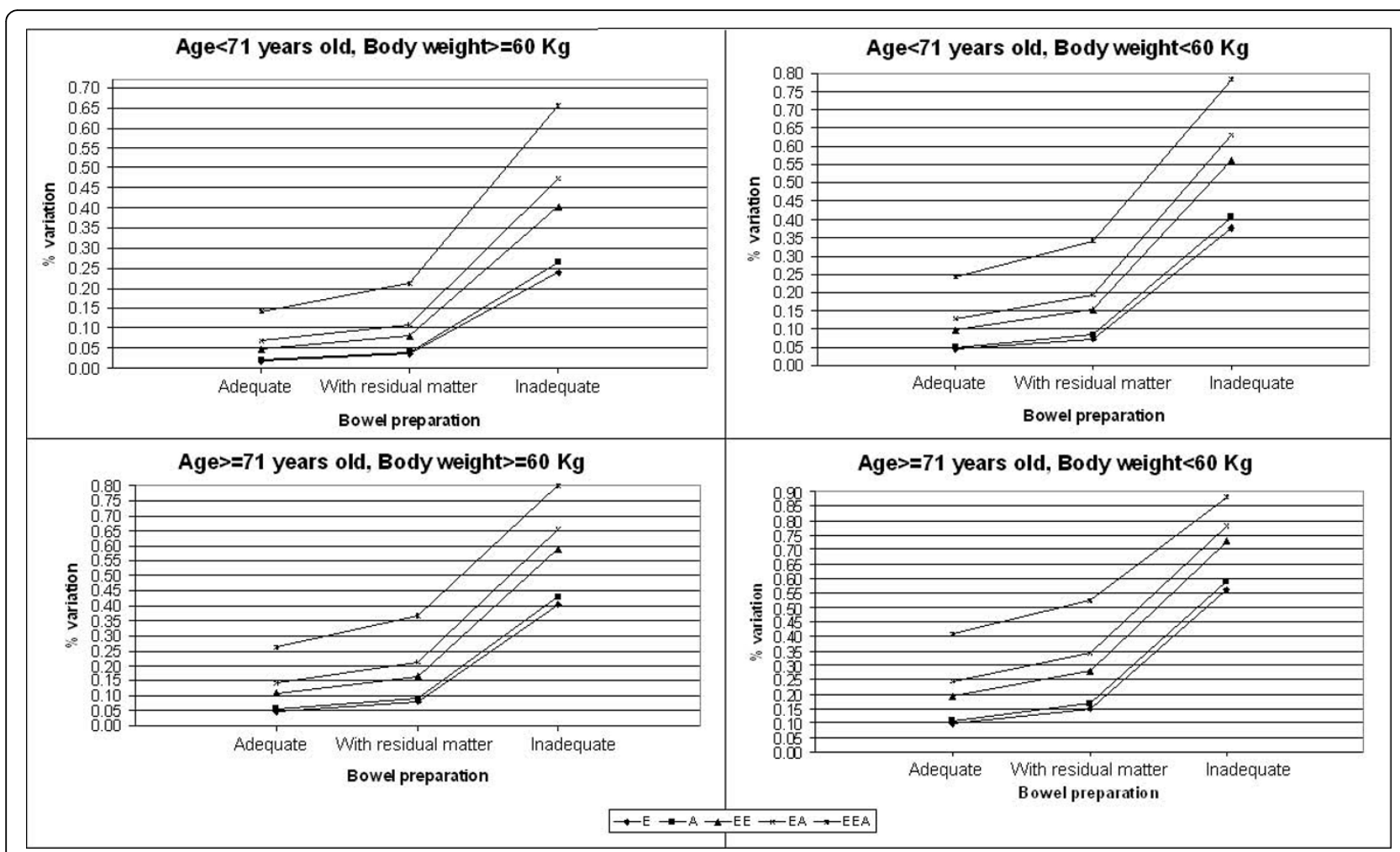

Figure 1 Percentage variations in colonoscopy success rates by patients' characteristics. This figure shows the percentage variations in colonoscopy success rate by level of experience of the endoscopists, age of the patient, body weight of the patients and bowel preparation. 
organizational aspects, but relevant data could probably be obtained quite easily by adapting our findings to different situations in different countries. We also collected no details on patients' satisfaction with the procedure, because this information is only collected at our centre in the context of clinical trials and we wished to avoid any Hawthorne effect on the endoscopists' routine practice.

Our study has shown a possible strategy for further improving the rate of successful cecal intubations, i.e. by modifying certain organizational aspects when deep sedation is used.

If a "difficult patient" (aged over 71 and weighing less than $60 \mathrm{~kg}$ ) has to undergo colonoscopy at the hands of a "less experienced non-specialist" (instead of a "highly experienced specialist"), then inadequate colon preparation reduces the chances of the colonoscopy being completed by $70 \%$. So, special attention should be paid to colon-cleansing practices for colonoscopies that are to be handled by a less experienced endoscopist. Moreover, if any unwanted effects of propofol infusion demanding AAI can be avoided by a careful management of sedation, then $60 \%$ of incomplete procedures could be successful. In other words, if a difficult colonoscopy is programmed (due to the patient's characteristics), then containing the need for AAI and improving bowel cleansing enables the successful completion of $90 \%$ of incomplete colonoscopies whatever the expertise of the endoscopist involved.

\section{Conclusions}

In conclusion, where there are workforce shortages and at large endoscopic practices where colonoscopies are handled by doctors with different levels of training and experience, the extensive use of propofol enables the standard success rate for screening colonoscopies to be approached. An excellent result can be achieved, in terms of the completeness of the procedures, especially if deep sedation is combined with a careful preliminary assessment of the workload so that patients listed for endoscopic procedures who might prove particularly difficult to handle (a situation that is readily identifiable from simple, known features) are not assigned to endoscopists without a high level of specialist experience.

\footnotetext{
Abbreviations

ASA: American Society of Anesthesiologists; CRF: Case Report Form; AAl: Active Anesthesiological Intervention; Cl: Confidence Interval; OR: Odds Ratio, ROC: Receiver Operating Characteristic
}

\section{Author details}

${ }^{1}$ Geriatrics Department, Geriatric Surgery Unit, General Hospital, Padova, Italy. ${ }^{2}$ National Research Council, Institute of Neuroscience, Padova Section, Italy. ${ }^{3}$ Department of Pharmacology and Anesthesiology, Anesthesia and Intensive Care Unit, Padova, Italy. ${ }^{4}$ Veneto Oncologic Institute, IRCCS, Padova, Italy.

\section{Authors' contributions}

$F C, O T, E P$, and BMD performed the conception and the design of the study $F C, N M, A A$, and FC performed the statistical analysis and the interpretation of the findings.

FC, NM, and AA performed the drafting of the article. BM performed a critical revision of the article for important intellectual content.

All authors read and approved the final manuscript.

\section{Competing interests}

The authors declare that they have no competing interests.

Received: 24 June 2010 Accepted: 20 October 2010

Published: 20 October 2010

\section{References}

1. Rex DK: Maximizing detection of adenomas and cancers during colonoscopy. Am J Gastroenterol 2006, 101:2866-77.

2. Inadomi JM: In search of quality colonoscopy. Gastroenterology 2008, 135:1845-62

3. Rex DK, Bond JH, Winawer S, Levin TR, Burt RW, Johnson DA, Kirk LM, Litlin S, Lieberman DA, Waye JD, Church J, Marshall JB, Riddell RH, U.S Multy-Society Task Force on Colorectal Cancer.: Quality in the technical performance of colonoscopy and the continuous quality improvement process for colonoscopy: recommendations of the U.S. Multi-Society Task Force on Colorectal Cancer. Am J Gastroenterol 2002, 97(6):1296-308.

4. Kozarek RA, Botoman VA, Patterson DJ: Prospective evaluation of a small caliber endoscope for colonoscopy after unsuccessful examination. Gastointest Endosc 1989, 35:333-5.

5. Brooker JC, Saunders BP, Shah SG, Williams CB: A new variable stiffness colonoscope makes colonoscopy easier: a randomized controlled trial. Gut 2000, 46:801-5.

6. Sanaka MR, Shah N, Mullen KD, Ferguson DR, Thomas C, McCullough AJ: Afternoon colonoscopies have higher failure rates than morning colonoscopies. Am J Gastroenterol 2006, 101:2726-30.

7. Wexner SD, Garbus JE, Singh JJ, The SAGES Colonoscopy Outcomes Study Group.: A prospective analysis of 13,580 colonoscopies. Surg Endosc 2001, 15:251-61.

8. Church JM: Complete colonoscopy: how often? And if not, why not? Am J Gastroenterol 1994, 89(4):556-60.

9. Rex DK, Imperiale TF, Portish V: Patients willing to try colonoscopy without sedation: associated clinical factors and results of a randomized controlled trial. Gastointest Endosc 1999, 49(5):554-9.

10. Harris JK, Froehlich F, Wietlisbach V, Burnand B, Gonvers JJ, Vader J-P: Factors associated with the technical performance of a colonoscopy: An EPAGE Study. Dig Liver Dis 2007, 39:678-89.

11. Ball JE, Osbourne J, Jowett S, Pellen M, Welfare MR: Quality improvement programme to achieve acceptable colonoscopy completion rates: prospective before and after study. BMJ 2004, 329:665-7.

12. Kondo S, Yamaji Y, Watabe H, Yamada A, Sugimoto T, Ohta M, Ogura K, Okamoto M, Yoshida H, Kawabe T, Omata M: A randomized controlled trial evaluating the usefulness of a transparent hood attached to the tip of the colonoscope. Am J Gastroenterol 2007, 102:75-81.

13. Vargo JJ: Propofol-mediated gastrointestinal endoscopy. Techniques in Gastrointestinal Endoscopy 2004, 6(2):60-4.

14. Rex DK: Colonoscopy turning the focus on quality. Dig Liver Dis 2002, 34:831-2.

15. ASA: New classification of physical status. Anesthesiology 1963, 24:111.

16. Ee HC, Semmens JB, Hoffman NE, Perth Teaching Hospitals Endoscopy Group: Complete colonoscopy rarely misses cancer. Gastrointest EndosC 2002, 55(2):167-71.

17. Anderson ML, Pasha TM, Leighton JA: Endoscopic perforation of the colon: lessons from a 10-year study. Am J Gastroenterol 2000, 95(12):3418-22.

18. Radaelli F, Meucci G, Minoli G, the Italian Association of Hospital Gastroenterologists (AIGO): Colonoscopy practice in Italy: a prospective survey on behalf of the Italian Association of Hospital Gastroenterologists. Dig Liver Dis 2008, 40:897-904.

19. Spinzi G, Dal Fante M, Masci E, Buffoli F, Colombo E, Fiori G, Ravelli P, Ceretti E, Minoli G, SIED Lombardia Working Group: Lack of colonic neoplastic lesions in patients under $50 \mathrm{yr}$ of age with hematochezia: a multicenter prospective study. Am J Gastroenterol 2007, 102:2011-15. 
20. Cremers Ml, Marques-Vidal P: Colonoscopies in Portuguese District Hospitals: a multicentric transverse study. Dig Liver Dis 2006, 38:912-7.

21. Garvican L: Planning for a possible national colorectal cancer screening programme. J Med Screen 1998, 5:187-95.

22. Twombly R: Recommendations raise workload issues for colon cancer screening. JNCl 2004, 96:348-50.

23. Waye JD: Completing colonoscopy. Am J Gastroenterol 2000, 95(10):2681-2.

24. Anderson JC, Gonzalez JD, Messina CR, Pollack BJ: Factors that predict incomplete colonoscopy: thinner is not always better. Am J Gastroenterol 2000, 95:2784-7.

25. Kim WH, Cho YJ, Park JY, Min PK, Kang JK, Park IS: Factors affecting insertion time and patient discomfort during colonoscopy. Gastrointest Endosc 2000, 52(5):600-5.

26. Bowles CJA, Leicester R, Romaya C, Swarbrick E, Williams CB, Epstein O: A prospective study of colonoscopy practice in the UK today: are we adequately prepared for national colorectal cancer screening tomorrow? Gut 2004, 53:277-83.

27. Hoda S: Cancer detection rates higher with deep sedation during colonoscopy. Digestive Disease Week 2009, Abstract 722.

\section{Pre-publication history}

The pre-publication history for this paper can be accessed here

http://www.biomedcentral.com/1471-230X/10/123/prepub

doi:10.1186/1471-230X-10-123

Cite this article as: Cardin et al:: Maximizing the general success of cecal intubation during propofol sedation in a multi-endoscopist academic centre. BMC Gastroenterology 2010 10:123.

\section{Submit your next manuscript to BioMed Central} and take full advantage of:

- Convenient online submission

- Thorough peer review

- No space constraints or color figure charges

- Immediate publication on acceptance

- Inclusion in PubMed, CAS, Scopus and Google Scholar

- Research which is freely available for redistribution 